\title{
Imaginarios del futuro tras la muerte de Nicanor Parra: renegociando la antipoesía como vehículo de protesta online
}

\author{
Imagining the future after Nicanor Parra's death: renegotiating antipoetry \\ as a vehicle for online protest
}

\section{María Victoria Guzmán}

Universidad del Desarrollo, Santiago, Chile

mv.guzmanaudd.cl

http://orcid.org/0000-0001-9342-7051

\section{Resumen}

El artículo examina las mediaciones y remediaciones de la imagen y obra de Nicanor Parra compartidas en Instagram en los días posteriores a su muerte usando la etiqueta \#nicanorparra. La importancia del antipoeta en el imaginario colectivo transforma su muerte en un sitio de memoria nacional. Un análisis del discurso de las imágenes y textos producidos y compartidos en la red social Instagram (IG) permite estudiar cómo estos "medios de memoria" articulan discursos contemporáneos sobre chilenidad y protesta. Los resultados indican que los usuarios construyen una imagen de Parra similar a la de un profeta moderno, cuyo mensaje de "anti-tud" les interpela a exigir cambios respecto de fenómenos como la inequidad económica y el impacto del desarrollo industrial en el medio ambiente. En conclusión, a través de la poesía de Parra expresada digitalmente, la imaginación mnemónica revela el trazado de imaginarios colectivos para el futuro de Chile.

Palabras clave: Nicanor Parra, creatividad vernacular, Instagram, poesía, protesta digital.

\begin{abstract}
This research examines the mediations and remediations of the image and work of Nicanor Parra shared on Instagram in the days after his death using the hashtag \#nicanorparra. The importance of the antipoet in the country's collective imagination transforms his death into an important site of national memory. Applying discourse analysis to the images and texts posted on Instagram (IG), allows us to study how these "memory media" articulate contemporary discourses of Chile and protest today. The results indicate that users build an image of Parra similar to that of a modern prophet, whose message of "anti-tud" challenges them to demand changes regarding issues such as economic inequality and the impact of industrial development on the environment. Through Parra's poetry, expressed digitally through vernacular creativity, the mnemonic imagination weaves new collective imaginaries for the future of the country.
\end{abstract}

Keywords: Nicanor Parra, vernacular creativity, Instagram, poetry, online protest. 


\section{Introducción}

El 23 de enero de 2018, diarios de todo el mundo informaban que Nicanor Parra, poeta y antipoeta, había fallecido a los 103 años. Un personaje cuasi inmortal, Parra concedió entrevistas y siguió escribiendo antipoesía incluso tras cumplir cien años y fue ampliamente destacado como uno de los autores más relevantes del siglo veinte: "hay un antes y un después de Parra", declaró Nial Binns (2006, p. xxix). El impacto de su muerte gatilló homenajes en redes sociales, donde circularon imágenes y textos con la etiqueta \#nicanorparra. Parra se había convertido en un símbolo con repercusiones y ecos más allá de su poesía y de su nacionalidad: un ecologista, una voz para los marginados, un profesor, un rebelde subversivo. Su transformación en ícono nacional hace que la memoria de su vida y obra trasciendan su figura histórica. El poeta Parra se convierte en un sitio de identidad en negociación y renegociación. Un análisis desde la perspectiva de los estudios de la memoria permite estudiar las publicaciones compartidas tras su muerte para revelar articulaciones contemporáneas sobre memorias y contra-memorias en Chile. ¿Qué nos dicen sobre lo que significa ser "anti" en el Chile de hoy? ¿Y qué es lo que estos discursos de memoria imaginan respecto del futuro?

En general, los poetas anteriores a Parra escribían poemas imponentes, con referencias herméticas y un lenguaje erudito (Morales, 2012). Parra desafió esa tradición y ridiculizó a esos "dioses del Olimpo" que juró "derribar". Su atractivo residía en su antipoesía, crítica y disruptiva, que se expresaba a través de chilenismos, proverbios y dichos populares, con el ritmo lúdico y dramático del habla cotidiana. A través de su humor sarcástico y su desdén por instituciones e ideologías, Parra se burló de la convención, ridiculizó a las instituciones estatales y religiosas, y se deleitó en crear confusión: fue percibido como un poeta de la gente, quien dio voz al "populacho" (Nómez, 2003; Morales, 2012). Su poesía era fruto de lo que escuchaba en las calles. Para él, los poetas eran la voz de la tribu (Foxley, 1989). La poesía, por lo tanto, debía ser aguda, para sobresaltar al lector y provocar una reacción: un artículo de primera necesidad y no un objeto de lujo para las clases acomodadas (Parra, 1969; González \& Dotremon, 2014).
Estudiar las mediaciones y remediaciones de la obra e imagen de Parra que circularon en redes sociales después de su muerte permite analizar cómo dichas representaciones de su imagen y antipoesía encierran una pluralidad de expectativas, ansiedades y ambiciones sobre el Chile de hoy y mañana. La identidad y la memoria colectiva son procesos continuos, en los que individuos y comunidades varían y adaptan su conexión al pasado a través de artefactos simbólicos que mantienen la memoria viva (Erll \& Rigney, 2012). Las redes sociales, e Instagram (IG) en particular, ofrecen un espacio para crear, compartir y recopilar dichos artefactos simbólicos como relatos de una experiencia en un momento y lugar específicos ( $\mathrm{Fa}-$ rinosi \& Micalizzi, 2016). Son esenciales para la construcción de identidades individuales y colectivas, productos creativos a través de los cuales hacemos sentido de nuestras vidas y conectamos pasado y futuro (van Dijck, 2017). Por ese motivo, la forma en que recordamos a Nicanor Parra más que ofrecer una mirada histórica y estática de su persona, puede revelar cómo nos articulamos en el presente y nuestras proyecciones y preocupaciones como comunidad hacia el futuro.

El paso del tiempo ha diluido el legado del miedo que dejó la dictadura militar: nuevas generaciones se han atrevido a marchar para exigir educación gratuita y de calidad, mientras que un movimiento feminista ha sacudido al país, con tomas en docenas de universidades y multitudinarias protestas callejeras. En octubre del 2019, un alza en el precio del transporte público detonó una de las revueltas sociales más intensas de la historia contemporánea chilena: miles de personas se volcaron al espacio público para manifestarse en contra de un sistema injusto y desigual. En ese contexto, es especialmente relevante estudiar cómo el legado de resistencia y crítica de Parra es adoptado y transformado con posterioridad a su muerte, sobre todo considerando que su trabajo buscó retratar a los chilenos tal y como eran y no como se suponía que debían ser (Grossman, 1975).

\section{Marco Teórico}

Históricamente, la cultura en Chile se ha representado a través de discursos paralelos: uno, en la esfera pública, altamente selectivo y construido de 
forma autoritaria desde arriba hacia abajo; y otro presente en las bases sociales, compuesto por subjetividades individuales e identidades comunales que no se ven representadas en las narrativas públicas (Larraín, 2001, 2010). Estudiar las creaciones culturales producidas y circuladas a través de Instagram posibilita una comprensión mayor de las diversas maneras en que recuerdos colectivos y populares se construyen -y son construidos- por ansiedades, aspiraciones y auto-representaciones del presente, desde una perspectiva no elitista (Hajek et al., 2016).

En ese sentido, la presente investigación se basa en el trabajo de Erll \& Rigney (2012) y su conceptualización de la memoria como performance más que reproducción exacta del pasado. La memoria no existe de por sí y sólo puede permanecer y convertirse en colectiva a través de procesos activos de recuerdo, procesos en los que la memoria es mediada a través de artefactos simbólicos; por ejemplo, publicaciones de Instagram (Harju, 2015). A su vez, estos artefactos simbólicos actúan como intermediarios entre las personas, creando un sentido de identidad común en el espacio y el tiempo (Erll \& Rigney, 2012).

Los estudios de memoria no sólo se refieren al pasado y presente, sino que también están ligados a las expectativas de lo que está por venir, introduciendo un modelo a través del cual articular y estudiar deseos y expectativas para el futuro. El concepto de memorias futuras o memorias del futuro está aún en desarrollo, por lo que este análisis se basa en el trabajo de Keighley \& Pickering (2012) sobre imaginación mnemónica, para estudiar las memorias del futuro que aparecen en las publicaciones de Instagram. Ello implica concebir la imaginación como una herramienta de la memoria, la cual es expresada creativamente en redes sociales como parte de un proceso creativo que contribuye a la creación de una identidad. Como señala Huyssen, "necesitamos tanto el pasado como el futuro para articular nuestras insatisfacciones políticas, sociales y culturales con el estado actual del mundo (...) los discursos de memoria son totalmente esenciales para imaginar el futuro" (Huyssen, 2006, p. 6).

La poesía puede ofrecer nuevas perspectivas sobre sociedad, memoria y política (Soguk, 2006; Chiriboga, 2013). Especialmente relevante es el análisis de Bleiker (2012) y sus investigaciones en torno a la relación entre estética y política, en las que destaca el potencial de la poesía para circular interpretaciones críticas y sorprendentes de la realidad. Como señala Bleiker (2012), “la poesía alude, no explica" (p. 145) haciendo posible que distintas comunidades construyan una identidad común, desafiando los límites de lo que puede ser visto, oído y pensado.

Por último, es relevante considerar las formas en que Internet, en general, y las redes sociales, en particular, han revolucionado la comunicación; cómo la información es generada, compartida y almacenada, y cómo distintas narrativas son distribuidas y recopiladas por sus usuarios (Van Dijck, 2007; Farinosi \& Micalizzi, 2016). Hoy, las redes sociales han colonizado la vida diaria y han transformado la forma en que damos sentido y significado a nuestras experiencias colectivas (Milan, 2015). Vinculando memoria y nuevos medios, Van Dijck (2007) acuñó el concepto de memorias mediadas para referirse a aquellas memorias "encarnadas en el cerebro o mente humanos, habilitadas por tecnologías y objetos, e insertas en un contexto social y cultural" (p. xiv). Estos productos creativos reflejan y construyen intersecciones entre el pasado y el futuro, recordando y proyectando la experiencia vivida. El estudio de estos artefactos simbólicos, los discursos que los construyen y la recepción que generan, pueden esclarecer la forma en que los medios reconfiguran y alteran nuestra relación con el pasado y con nosotros mismos (Van Dijck, 2007; Erll \& Rigney, 2012).

Las plataformas digitales han permitido a sus usuarios crear, producir y desarrollar narrativas propias, tanto de forma comunitaria como individual. Numerosas investigaciones sobre las redes sociales han revelado su potencial como espacios de articulación y negociación de auto-representaciones, a medida que se despliegan distintos aspectos identitarios en publicaciones, comentarios, fotografías y likes. Distintos investigadores han estudiado cómo Facebook y Twitter, por ejemplo, posibilitan performances de identidades de género y queer (Vivienne \& Burgess, 2013; Duguay, 2015; Guta \& Karolak, 2015), permiten desafiar y reescribir narrativas hegemónicas (Farinosi \& Micalizzi, 2016; Nyabola, 2017) y representar identidades y performances del "yo" (Hogan, 2010; Zappavigna, 2016). 
A pesar de lo anterior, la mayoría de los análisis se refiere a los aspectos técnicos de dichas plataformas y no lo suficiente al significado y la importancia de las imágenes y textos compartidos. Una excepción es el estudio de Becker (2017) sobre el potencial de Instagram para democratizar y generar agencia en la medida que es usado como una herramienta comunitaria a través de la cual crear y circular imágenes y representaciones propias, articulando discursos que han sido excluidos de narrativas tradicionales o hegemónicas. Burgess (2007), en tanto, ha conceptualizado la creatividad vernacular como producciones culturales cotidianas de personas comunes, quienes modifican y recombinan recursos y símbolos familiares de forma creativa, para dar sentido a sus experiencias cotidianas. Estos productos creativos ofrecen un espacio de resignificación, donde distintos grupos participan activamente de la creación de significados y representaciones. Así, Instagram y otras redes sociales constituyen canales de difusión a los que antes no se tenía acceso, empoderando a usuarios con herramientas innovadoras para la construcción y performance de identidades a través de nuevas prácticas culturales (Martín-Barbero, 2006; Van Dijck, 2007).

\section{Marco Metodológico}

Los métodos cualitativos son la herramienta más apropiada para explorar temas de comunicación y memoria, pues permiten encontrar "significado en el contexto" (Merriam, 2009, p. 2) y comprender los procesos a través de los cuales las personas elaboran el sentido de sus experiencias en un momento y lugar específicos. Es sólo a través de una lectura detallada de los datos, en vez de la cuantificación que estas mediaciones y remediaciones de imágenes y poemas, y los significados y negociaciones contenidos en ellos, pueden ser comprendidas.

Este estudio se enmarca en una epistemología constructivista (Lather, 2017) que considera la realidad como un constructo social, compuesta por un complejo conjunto de entendimientos, articulaciones y representaciones de significados (Merriam, 2009). Ello considera la densidad y diversidad de posiciones y perspectivas expresa- das en las publicaciones. Este enfoque es particularmente adecuado para estudiar la memoria, pues ésta es también una construcción social más que una copia del pasado y está permanentemente moldeada por la necesidad de hacer inteligible nuestra realidad y nuestra relación con las comunidades a las que pertenecemos (Kearney, 2013).

Lo anterior se complementa con una posición crítica, pues el presente estudio está enfocado en desafiar y transformar el statu quo (Merriam, 2009). Numerosos académicos han destacado que la memoria no sólo permite comprender las experiencias: también tiene la capacidad de subvertir el poder y desafiar costumbres impuestas y naturalizadas (Keightley \& Pickering, 2013). Un enfoque crítico permite ir más allá de una interpretación de discursos y producir conocimiento práctico y emancipatorio que contribuya a generar cambios (Lather, 2017).

Bajo este marco epistemológico, realizamos un análisis textual de las publicaciones compartidas en Instagram tras la muerte de Nicanor Parra. Se reconocen discursos que iluminan la construcción social de la identidad chilena actual a través de las diferentes representaciones que aparecen, sus suposiciones subyacentes y la comprensión del mundo que revelan (McKee, 2003). Kearney (2013) señala que el análisis de discurso ofrece oportunidades especialmente ricas para interactuar con representaciones gráficas y textuales, pues permite al investigador observar la producción social de ideas y valores y la forma en que dichas ideas y valores se contradicen o respaldan mutuamente, a medida que diferentes discursos compiten por detentar poder y autoridad respecto de qué puede ser considerado como verdadero.

El análisis se complementa con las pautas de Rose (2012) de análisis de discurso en imágenes, atendiendo a qué grupos de imágenes aparecen, los objetos que reproducen y las asociaciones y conexiones entre ellos. A pesar de la familiaridad con algunas de las imágenes, hemos considerado el material con una mirada fresca, analizando en profundidad la información para encontrar tanto lo visible como lo oculto. Así, logramos identificar los discursos articulados en las imágenes analizadas y el significado latente detrás de ellas (Fürsich, 2009; Rose, 2012). 
Usando el software 4kstagram se descargaron las imágenes subidas a Instagram con la etiqueta \#NicanorParra entre el 23 de enero de 2018 y el 27 de enero del mismo año. El resultado fue de más de 10.000 publicaciones, ilustrando la significancia de la muerte de Parra en el imaginario nacional. Para realizar un análisis de datos con una cantidad de material manejable se seleccionaron trescientos archivos consecutivos subidos el 23 de enero, como muestra representativa. Sólo consideramos publicaciones públicas, despejando eventuales problemas éticos relacionados con la privacidad. El acceso y uso cumple íntegramente con las normas establecidas por Pace \& Livington (2005): el contenido es de fácil acceso para cualquier persona con una cuenta de Instagram, no requiere de una contraseña, no es de naturaleza delicada y se respetan los términos y condiciones de Instagram.

Al conjugar análisis textual y una metodología visual es posible interrogar qué se está diciendo, por quién y bajo qué circunstancias; qué es lo que se recuerda de la vida y trabajo de Parra y qué no; $y$, sobre todo, qué es construido a través de estas publicaciones, qué contradicciones aparecen y bajo qué contextos. A través del análisis de discurso se identifican "los supuestos ideológicos y culturales subyacentes al texto" (Fürsich, 2009, p. 240) acerca de la memoria e identidad chilenas y la forma en que pueden contradecir o repetir discursos hegemónicos.

\section{Resultados}

\section{1. "Anti-tud": las Enseñanzas de un Profeta}

Parra se autodenominó a sí mismo como "antipoeta", una declaración revolucionaria que impactó al mundo literario y fijó las bases de su obra radical (González \& Dotremon, 2014). El estudio de las publicaciones evidencia que el prefijo caló hondo: en las trescientas publicaciones estudiadas, la etiqueta más numerosa después de \#nicanorparra fue \#anti. Muchos de los usuarios aplicaron el término lúdicamente: una usuaria se describió a sí misma como una "anti-adulta" y un usuario se refiere a su "anti-trabajo".
Uno de los resultados más significativos es cómo los usuarios articularon la "anti-tud" de Parra, construyendo su actitud crítica como una característica que le otorgase al anti-poeta un estatus divino o espiritual. En las imágenes y textos publicados, Parra es descrito como un individuo sobrenatural o un profeta, un Jesús o Zaratustra chileno. Los usuarios lo describen repetidamente como "inmortal", "el grande", "eterno" o como alguien que "vivirá por siempre". El texto de una publicación dice "103 años en la tierra \#nicanorparra", sugiriendo que vendrán más; otro, agradece a Parra "dejarnos tanto a nosotros los mortales". La etiqueta \#antimuerte fue ocupada numerosas veces y muchas publicaciones incluyeron el conocido verso de Parra que dice "el compadre sabe lo que hace", dando a entender que Parra estaba en control de la decisión de morir o, incluso, que su "anti-tud" podría ayudarle a evitar la muerte.

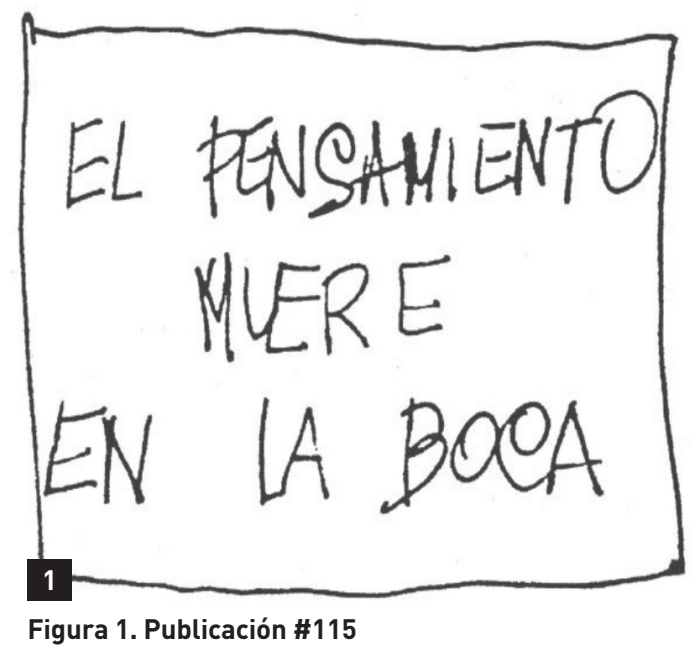

“Como dijeron por ahí, lo único que le faltaba al DonLicanor para alcanzar la inmortalidad. Grande \#nicanorparra \#chileansbelike"

Más aún, en las publicaciones se describe a Parra como una "luz", una referencia con fuertes connotaciones religiosas y espirituales, y se le desea un "buen regreso a la fuente". El ícono de dos manos juntas en oración fue repetidamente usado, al igual que la frase "llévame contigo". Varios de los usuarios le agradecieron a Parra haberlos iluminado: una publicación afirma: "rompiste con tu poesía muchos muros que me impedían ver lo que ahora veo. Gracias por todo". De forma similar, un gran número de imágenes muestra a Parra enseñando 
o escribiendo en un pizarrón, imágenes acompañadas de descripciones de lo que aprendieron del anti-poeta: a valorar sus raíces, a ver cosas nuevas, a amar la poesía. Esto fue resaltado también con el uso de etiquetas como \#enseñar, \#profesor o \#maestro.

Un texto dice "Hasta siempre \#DonNica tu \#antipoesia nos enseñó a ser creativos, rebeldes e irreverentes. Tu legado emprende hoy su vuelo para siempre". Como dijo Milan, Parra fue "el único poeta latinoamericano que fue realmente revolucionario" (en Binns, 2006). Una ilustración ampliamente usada representa a un Parra de sonrisa traviesa, levantando ofensivamente el dedo medio de cada mano, mientras dos ángeles desnudos lo llevan al cielo. Bajo el trío aparecen las palabras del famoso artefacto: "llore si le parece, yo por mi parte, me muero de risa".

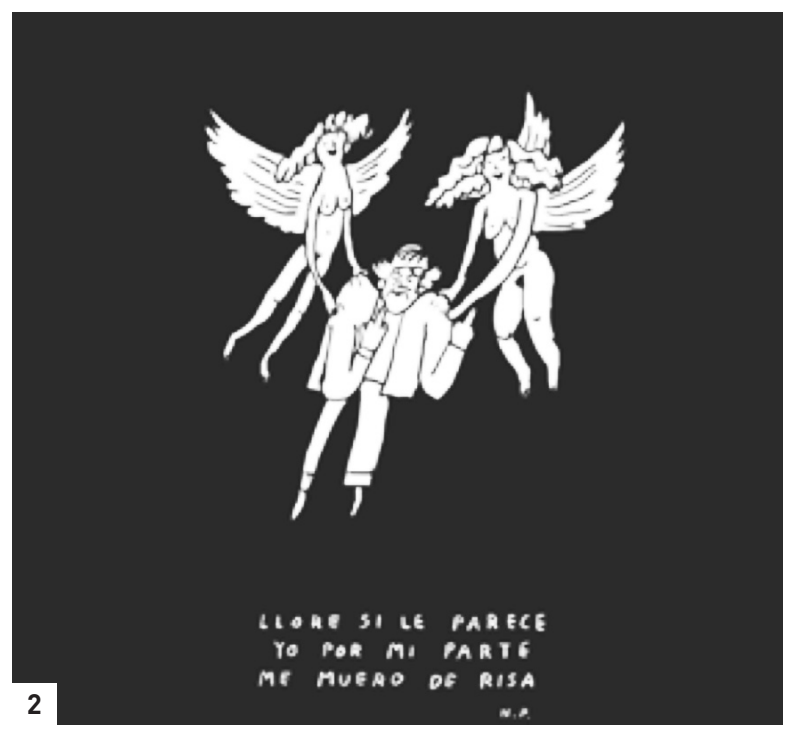

Figura 2. Publicaciones \#172, \#180, \#184, \#241, \#247, \#285, \#286

Un significante con connotaciones de subversión o rebeldía que apareció numerosas veces es el de las manos. La mayoría de las publicaciones con fotografías de Parra muestran imágenes en las que aparece escondiéndose tras sus manos o levantándolas de forma hostil. Asimismo, varios usuarios crearon sus propios dibujos o ilustraciones, la mayoría de los cuales da protagonismo a las manos del antipoeta, que aparecen levantadas con el puño en el aire o con los dedos apoyados en el rostro. Las manos, especialmente puños o palmas levan- tados, traen a la mente ideas de hostilidad, rebelión o, incluso, revolución: son una representación visible de la "anti-tud" de Parra. Haciendo eco de ello, uno de los poemas más citados fue "Montaña Rusa", en el cual Parra invita al lector a un viaje osado, advirtiéndole que no se disculpará si se baja "echando sangre por boca y narices". Es una de sus obras más desafiantes y críticas, en el que se refiere al poder destructivo de su antipoesía. Los usuarios se suben simbólicamente a la montaña rusa. Uno escribe: "Dejémonos de solemnidades y pasemos a las montañas rusas". Y otro: “ $i Q u e ́$ bien que viniste con tu montaña rusa poética!".

Como señalamos, la antipoesía de Parra es radical, escéptica, irónica y desarticula todo lo que era considerado apropiado o correcto, exponiendo un mundo postmoderno, lleno de contradicciones y alienación. Las publicaciones reproducen esa actitud desafiante y confrontacional y hacen eco de esa postura radical al destacar problemas sistémicos ligados al modelo neoliberal, en particular, la desigualdad económica y la degradación del medioambiente. Larraín se ha referido a lo primero, advirtiendo que "la gente no tiene certezas mínimas sobre su empleo, educación, vivienda o salud. La mayoría de los chilenos viven en una inseguridad extrema con respecto a su futuro" (2010, p. 18).

A pesar de lo anterior, Chile sigue siendo presentado al mundo como un campeón económico y un país desarrollado, donde la gente viaja, compra y gasta (Larraín, 2010; El Mostrador, 2020). Esa contradicción es subrayada por los usuarios, quienes asumen la "anti-tud" de Parra para desafiar el discurso de bienestar hegemónico. Las publicaciones exponen una sociedad individualista, obsesionada con la búsqueda de la comodidad y el consumo, que convive con una profunda brecha social y económica. Algunas de las frases de Parra más citadas en las publicaciones ilustran este malestar: los artefactos "¡Para qué hemos nacido como hombres. Si nos dan una muerte de animales!" y "Hay dos panes. Usted se come dos. Yo ninguno. Consumo promedio: un pan por persona" fueron algunos de los más usados, así como el poema "Coplas del vino" cuyo verso más citado fue "El pobre toma su trago / Para compensar las deudas / que no se pueden pagar / Con lágrimas ni con huelgas". En su mayoría, estos textos fueron acompañados de fotos de Parra en blanco y negro, mirando serio a la cámara. Su mirada es directa y exige el cambio, instando a los usuarios a actuar. 


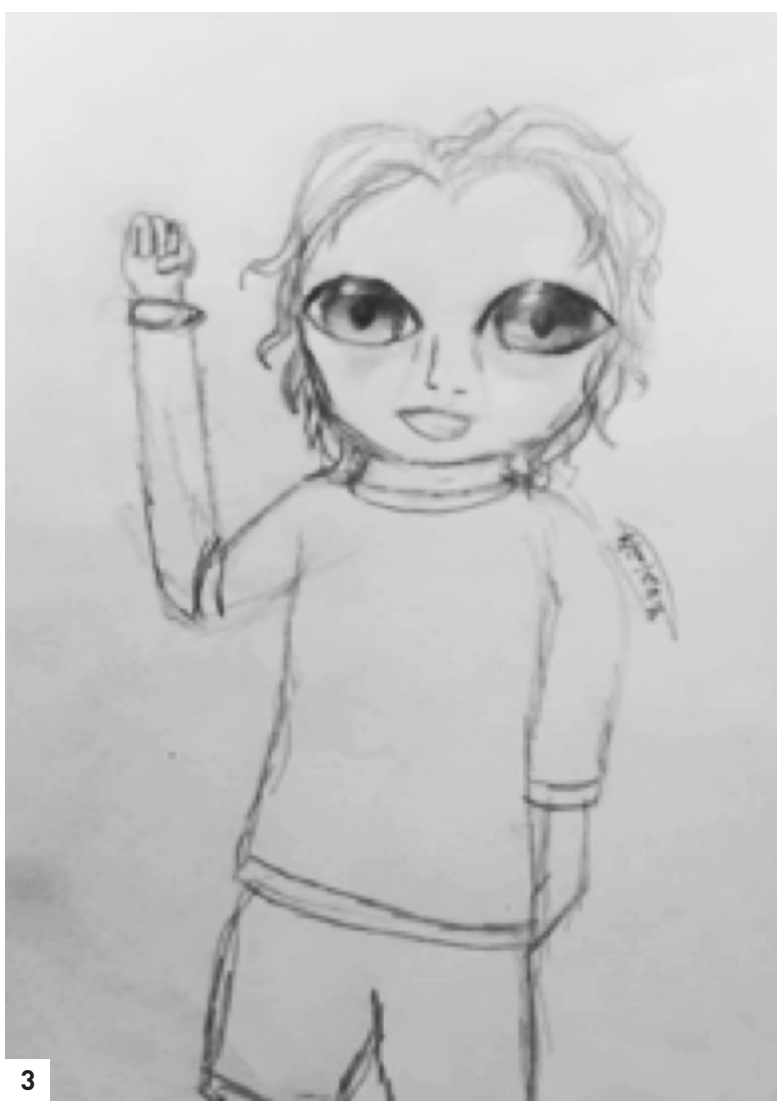

Figura 3. Publicación \#34

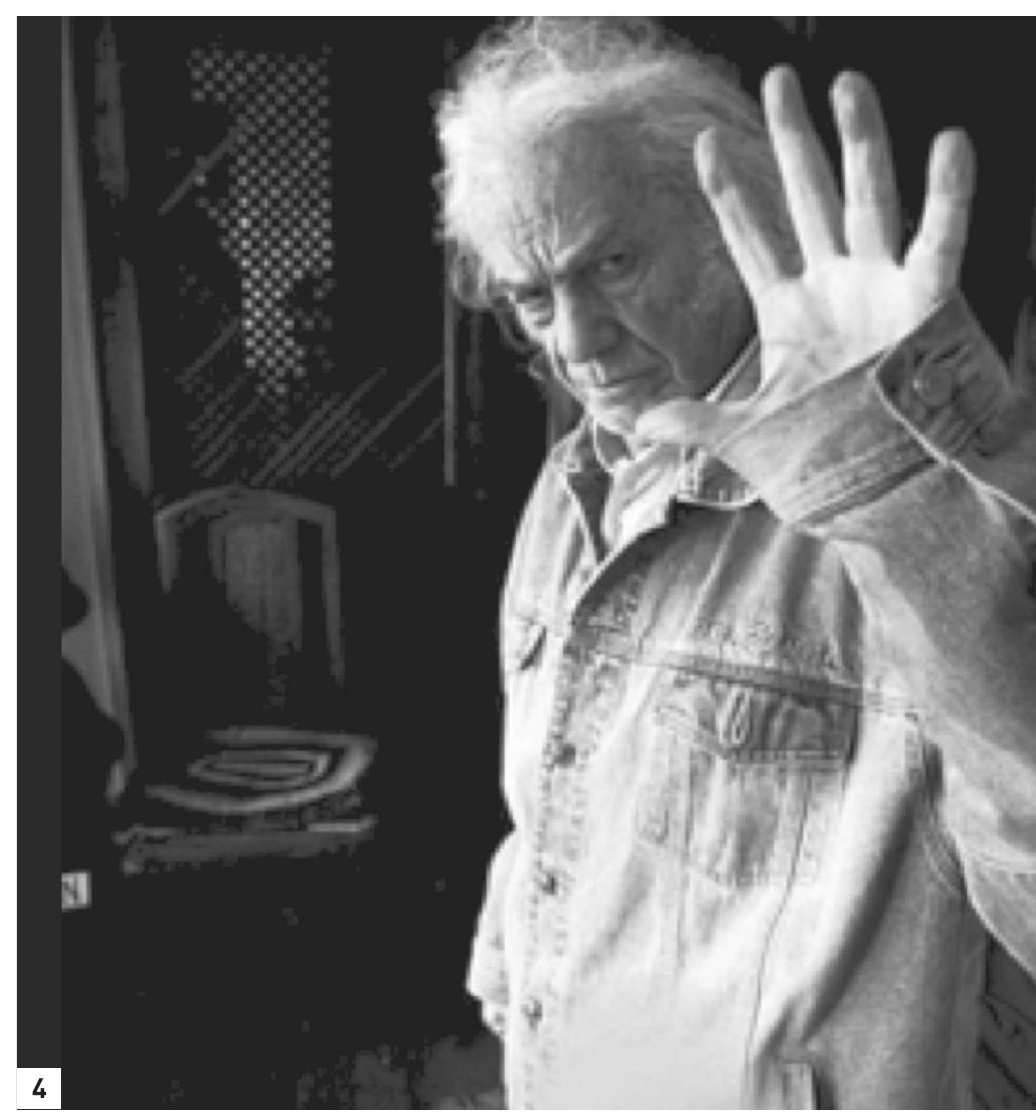

Figura 4. Publicación \#63
Las publicaciones destacan inquietudes respecto al medioambiente y el impacto del progreso económico en el mismo. Es relevante destacar que Parra fue uno de los primeros eco-poetas, un activista en contra del desarrollo económico desmedido, que luchó contra la enajenación contemporánea de mente, cuerpo y medioambiente al describir una sociedad desintegrándose y contaminando tierra y aguas (Binns, 2006). En las publicaciones, las demandas ecológicas se articularon a través de la elección de versos e imágenes específicas, los cuales evidencian una disposición a desafiar lo que se considera normal o tolerable en relación con el medioambiente. Se usaron artefactos de Parra como "Recuerdos de infancia: los árboles aún no tenían forma de muebles y los pollos circulaban crudos por el paisaje" o "El error consistió en creer que la tierra era nuestra cuando la verdad de las cosas es que nosotros somos de la tierra". Varios usuarios citaron el poema "Tiempos modernos", específicamente la estrofa "nubes malditas revolotean en torno a volcanes malditos / Embarcacio- nes malditas emprenden expediciones malditas / Árboles malditos se deshacen en pájaros malditos: / todo contaminado de antemano". Distintos estudios han vinculado la identidad chilena a las tierras y mares de su territorio (Nómez, 2003; Larraín, 2010); bajo esa perspectiva, degradar un paisaje tan integral a nuestra identidad nacional implica una degradación de las propias personas que lo habitan.

Las publicaciones demuestran que la "anti-tud" de Parra actúa como dispositivo crítico, revelando nuevos discursos respecto del estado del país. La antipoesía se configura simbólicamente con la capacidad de generar rebelión y desafiar la autoridad y Parra es articulado como el portador de este mensaje. Lo anterior respalda las conclusiones de Bleiker (2012), que plantea la poesía como un vehículo para la reflexión política. Los usuarios se apropian de la anti-poesía para relevar problemas que han permanecido ocultos o silenciados y los versos, artefactos y estrofas de Parra son activa- 
mente usados para exigir mejores condiciones de vida, cambios profundos al orden económico y una mayor protección al medioambiente. Siguiendo a Van Dijck (2007), las publicaciones reflejan un compromiso activo y una expresión de agencia, pues a través de éstas, el público exige el derecho a participar y ser escuchado. Autores como Rowe \& Schelling (1991) han propuesto que los medios pueden ser un lugar de resistencia al control externo, una dimensión de memoria social en la cual el público "participa activamente en la construcción de mensajes". Asimismo, Shellhorse (2017) ha teorizado la "anti-literatura" como un espacio para la articulación de lo subalterno, lo femenino, lo marginalizado, complicando discursos considerados de sentido común; en este caso, problematizando los efectos nocivos de un progreso económico descontrolado.

\subsection{Quiebre / Futuro}

Abordar la figura y obra de Parra como un sitio de memoria implica el riesgo de que emerjan memorias de pasados traumáticos, referidas a la dictadura o a los complejos años que siguieron. Sin embargo, la tendencia fue radicalmente distinta, pues las publicaciones construyen una memoria colectiva que se proyecta.

El propósito de los anti-poemas era derribar el statu quo, desenmascarando y desmitificando instituciones decrépitas como el Estado y la iglesia (Binns, 2006). Para el propio Parra, el fin último del antipoeta es hacer estallar los cimientos de instituciones obsoletas: el antipoema debía actuar como la punta de una aguja, reventando un globo (Parra \& Neruda, 1962; Benedetti, 1972). Como señala una de las publicaciones, "no veo para qué tanta alharaca: ya sabemos que el mundo se acabó". Sin embargo, si consideramos la idea de "tradición de la ruptura" de Paz (Chiriboga, 2013), la crítica que derriba y desenmascara es al mismo tiempo catalizadora de nuevos ciclos de creación: la "anti-tud" se revela como una fuerza creativa y un agente de cambio.

Tiene sentido que, en momentos de turbulencia, cuando ya no se puede confiar en lo que sabíamos o creíamos, se busquen respuestas en el futuro: a

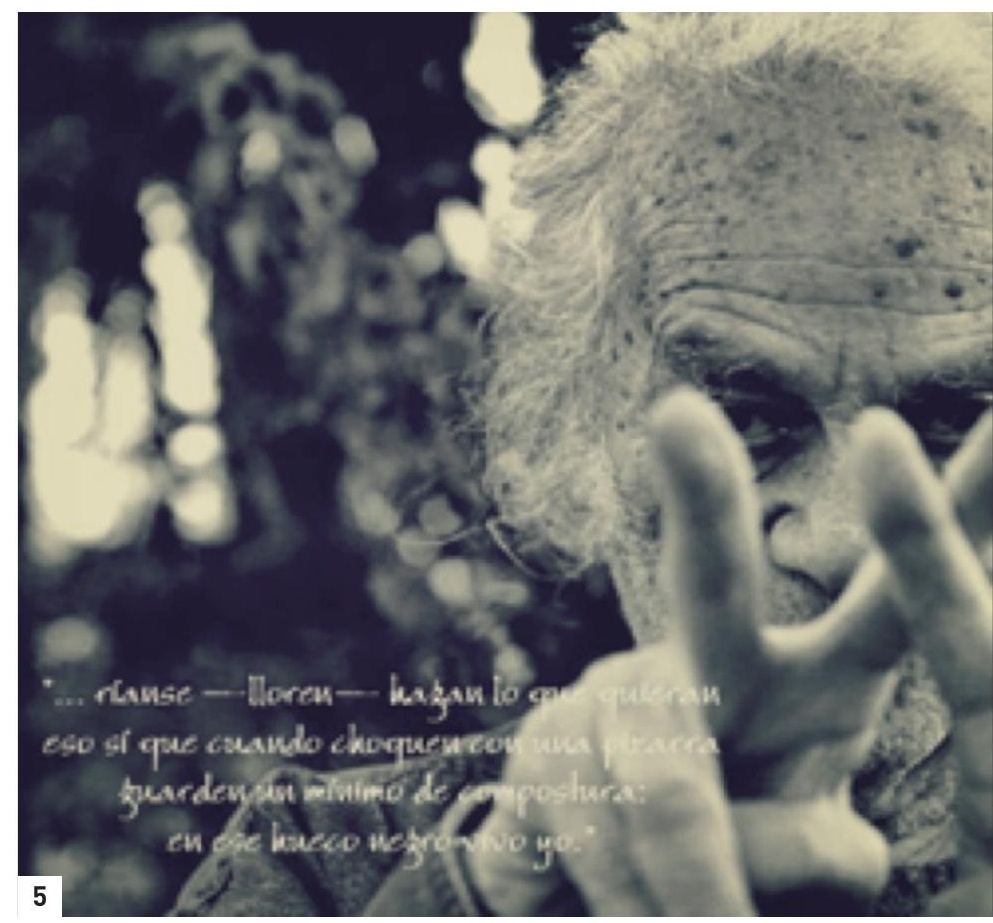

Figura 5. Publicación \#276

fin de cuentas, las memorias se forman a través de narrativas, animadas por un ideal de quién queremos ser (Frith, 1996). Esto se aplica en especial a las identidades nacionales, las cuales son reevaluadas en tiempos de crisis (Larraín, 2001). Tras una demolición simbólica de creencias y valores, no queda otra alternativa que empezar a construir sobre las ruinas e imaginar nuevas posibilidades.

De esta forma, emulando la "anti-tud" de Parra, los usuarios se manifiestan en contra de problemas actuales con discursos novedosos que tienen el potencial de constituir una base para levantar nuevos futuros. En ese sentido, el concepto de un "mañana" aparece recurrentemente en las publicaciones analizadas. El poema "El Último Brindis" fue citado repetidas veces, especialmente su verso "Sólo nos va quedando el mañana: / Yo levanto mi copa / Por ese día que nunca llega / Pero que es lo único / De lo que realmente disponemos." Del mismo modo, un artefacto sobre el medioambiente fue citado en reiteradas ocasiones, tanto en imágenes como en textos: "Buenas noticias: la tierra se recupera en un millón de años. Somos nosotros los que desaparecemos". Bajo una imagen con esas palabras, un usuario escribió el siguiente texto: "Es difícil creer con cuánta fuerza tratamos de separarnos de la naturaleza, cuando somos 
una pequeña parte de ella, y debiésemos actuar en consecuencia \#nicanorparra". Nuevamente, se articula a Parra como un profeta que ha confiado a los usuarios una misión o mandato: un usuario advierte "recuerden amigos chilenos lo que $\mathrm{Pa}$ rra nos ha pedido" y otro se pregunta "Don Nica, ¿cómo cree que el arte puede construir la historia de Chile?".

Adicionalmente, la mayoría de las publicaciones están conjugadas en tiempo verbal futuro o condicional: "yo haré", "hagámoslo vivir" y "será" son algunos ejemplos. La idea del futuro también aparece en remediaciones del famoso artefacto de Parra con las palabras "voy y vuelvo" sobre una cruz vacía. Los usuarios representaron esta idea de forma recurrente como etiqueta, en imágenes y a través de textos. Frases como "Dijiste alguna vez: 'Voy y vuelvo', ojalá vuelvas"; "VUELVA CUANDO QUIERA DON NICANOR"; o “Don \#NicanorParra: vaya nomás, pero vuelva pronto" son algunos ejemplos, que vuelven a ejemplificar la construcción colectiva de Parra como un ser inmortal o espiritual. Una publicación más extensa aconseja a Parra: “Don Nica. Cáguese de la risa por ahí, en el Universo. ¿El Olimpo? Para qué, de ahí descendieron los poetas. Vuelva pronto".

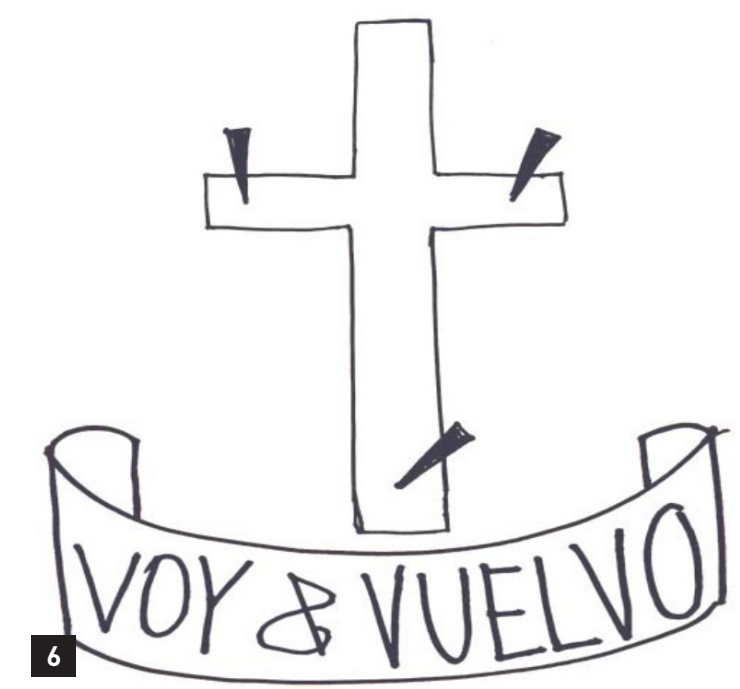

Figura 6. Publicaciones \#18, \#93, \#207
Las reflexiones compartidas respecto del mañana nos conducen al poder de la imaginación mnemónica que, a través de prácticas y procesos cotidianos - como las mediaciones y remediaciones de Instagram-generan nuevos y múltiples significados, incluyendo narrativas transformadoras de sucesos pasados que cuestionan y desafían relatos institucionalizados de los mismos, generando un marco para la acción social y política en el presente (Keighley \& Pickering, 2012). En ese sentido, en las publicaciones se menciona recurrentemente al "hombre imaginario", el protagonista de uno de los poemas más reconocidos de Parra. Los usuarios identifican una y otra vez a Parra como ese hombre imaginario, nuevamente, imaginándolo como un ser superior, que nos está observando y que volverá. Aseveraciones como "nos ha dejado imaginariamente", "el corazón del hombre imaginario volverá a latir" o "el hombre imaginario siempre vivo", y el uso de las etiquetas \#imaginario y \#muerte insisten en la idea de una muerte que no es definitiva.

Un usuario escribe "\#NicanorParra ha muerto, el único poeta que he realmente leído y disfrutado. Léanlo, por Dios, aún tienen tiempo". La pregunta es, ¿tiempo para qué?, ¿qué se avecina o qué va a suceder que es necesario leer a Parra? En ese sentido, muchas de las publicaciones hicieron referencia a las protestas estudiantiles, elocuentemente usando fotos donde aparece una imagen de Parra sobre las mismas. Otras contenían imágenes de arte callejero o graffiti, el cual ha sido estudiado como una herramienta usada por grupos marginalizados para reivindicar la calle como espacio público, negociar su identidad y desafiar narrativas dominantes (Cardalda \& Tirado, 2001). Esto constituye un contraste extraordinario respecto de datos del 2006 en que un $66,1 \%$ de los entrevistados respondieron que no participarían en protestas públicas contra el gobierno o empresas privadas (Programa de las Naciones Unidas para el Desarrollo, 2006).

Así, las publicaciones se articulan como reflejo de una generación conectada y comprometida con el cambio, especialmente en relación a un sistema económico que es percibido como manipulado por unos pocos en desmedro de la mayoría (Hormazábal, 2017). La sociedad chilena vivió con miedo por muchos años, incluso una vez terminada la dictadura (Larraín, 2010). Sin embargo, han apa- 


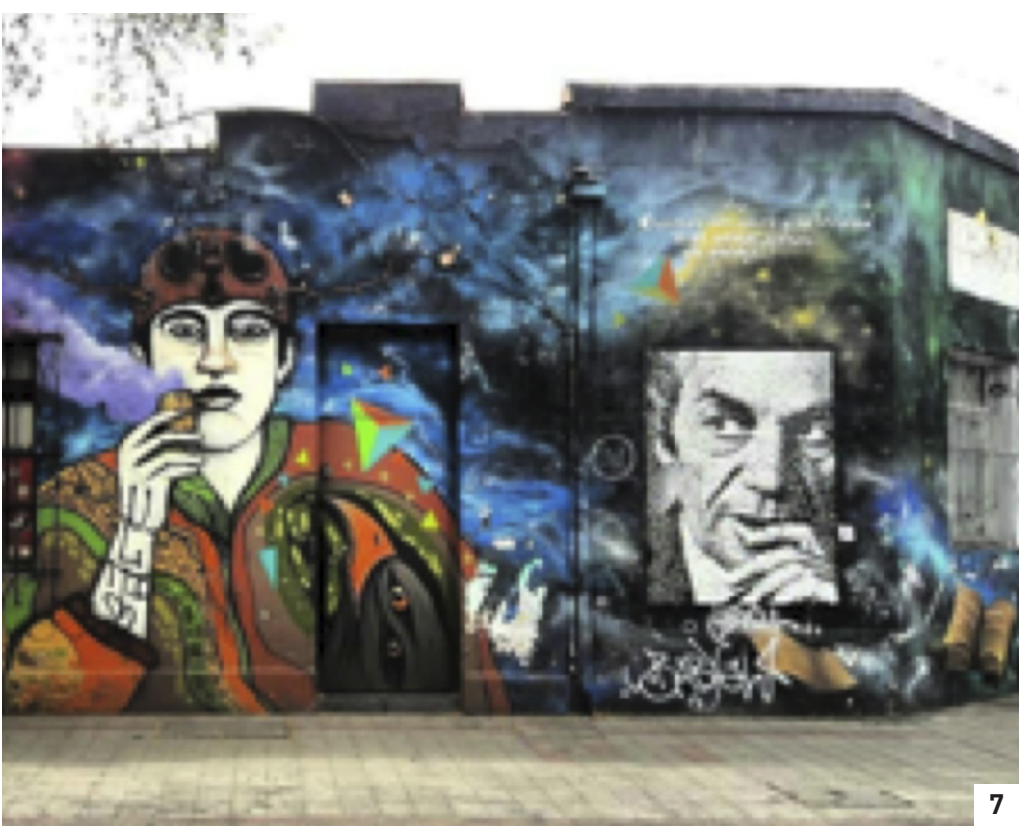

Figura 7. Publicación \#169

Figura 8. Publicación \#296

Figura 9. Publicación \#52

recido nuevos movimientos sociales liderados por jóvenes que no vivieron el terror de la autoridad militar. El movimiento estudiantil de 2006 y 2011 y nuevos pactos políticos y electorales han exigido cambios socioeconómicos radicales para abordar la desigualdad. El 2018 el país fue testigo de un movimiento feminista que tensionó los cimientos y valores de gran parte de las instituciones del país, y el 18 de octubre de 2019 protestas masivas gatillaron un proceso constitucional para reemplazar la carta magna aprobada en dictadura, catalizando conversaciones sobre qué tipo de país quieren los chilenos para el futuro.

El poder circula (Foucault, 1991) y las publicaciones son eco de una ciudadanía empoderada para exigir, protestar y ocupar. Una publicación dice: "Los actos poéticos también deben contener política". Otra indica "Me trago la pena, me la trago para más tarde vomitarla en el nombre de todos los poetas de Chile"; cabe preguntarse qué forma tomará (o ha tomado) ese "vómito". Siguiendo a Hall (1996), estas representaciones del futuro son actos de agencia, en los que las personas representan su identidad actual e ideales futuros; en este caso, luchando contra un presente insa-

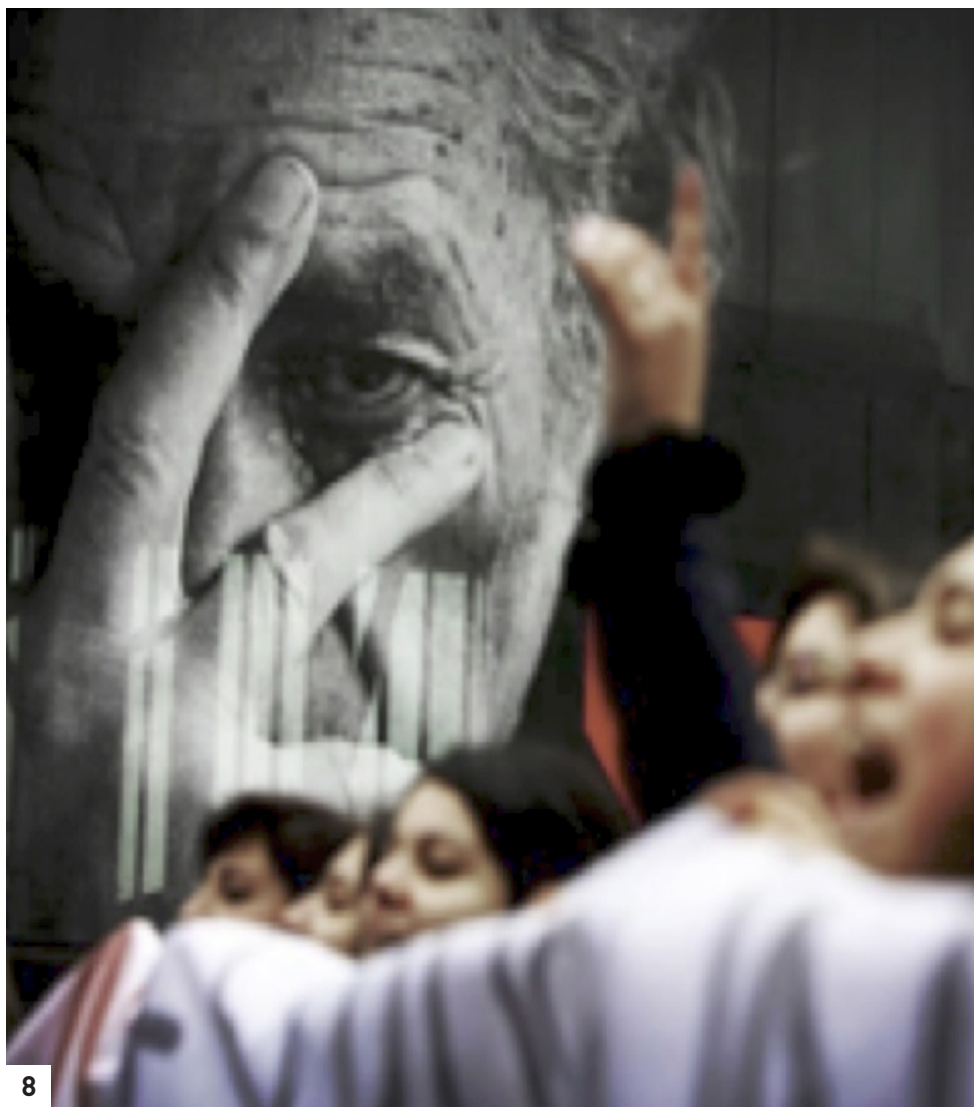

9

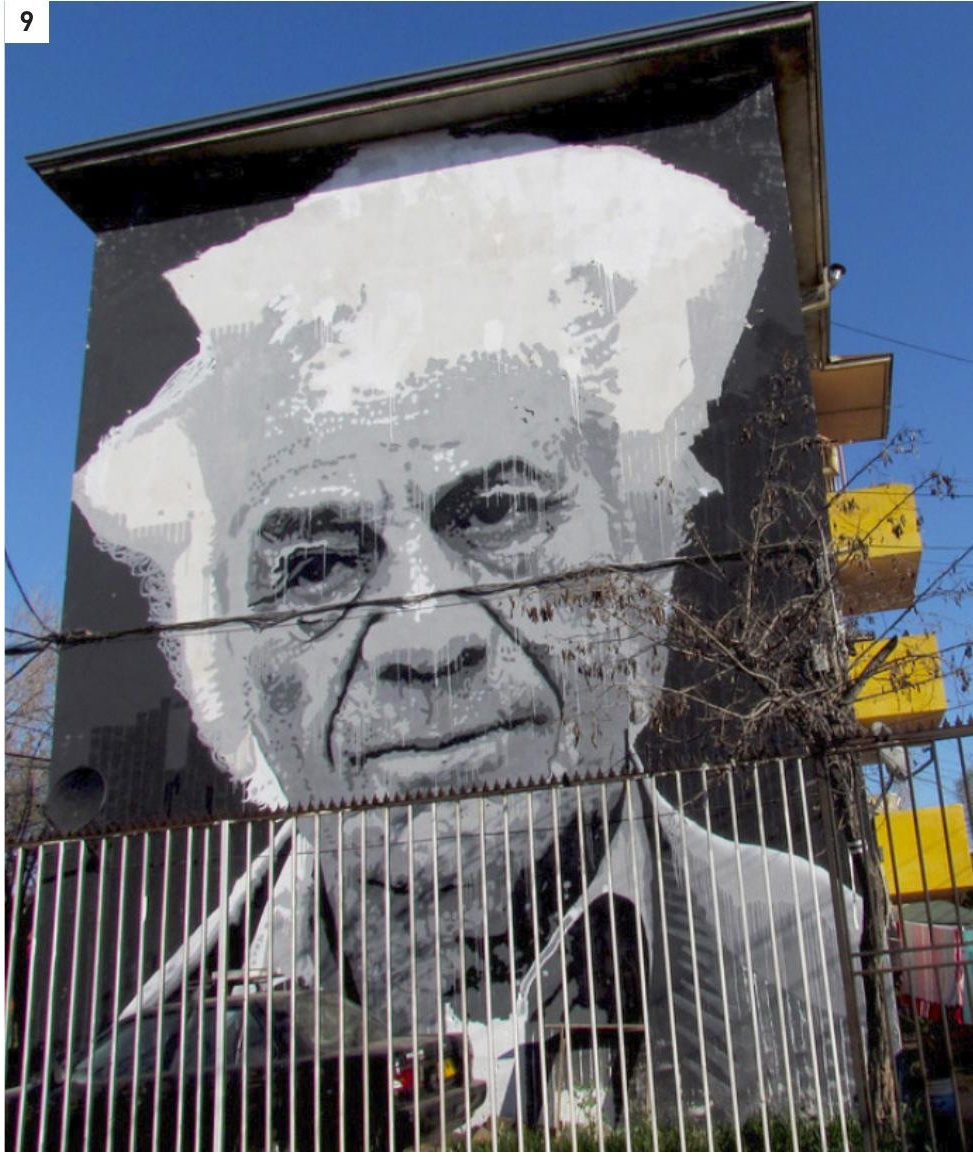


tisfactorio y soñando con un mañana más justo. Las mediaciones y remediaciones de las publicaciones son herramientas de autoformación y conexión que guían a la identidad y las memorias futuras: son parte de la narración del proyecto de quién queremos ser.

\section{Conclusión}

El propósito de esta investigación fue examinar articulaciones contemporáneas de memoria e identidad chilena con el objetivo de aportar a nuestra comprensión actual sobre el tema, sobre todo considerando el contexto de protestas masivas, polarización y revuelta social que han marcado los años recientes. Siempre ha sido complejo hablar de una identidad chilena, no sólo porque las identidades son plurales y constantemente cambiantes (Hall, 1996; Martín-Barbero, 2006), sino que también por el impacto en Chile del colonialismo, el elitismo, la dictadura de Pinochet y las políticas neoliberales (Larraín, 2010; Subercaseaux, 2016). La muerte de Nicanor Parra brindó una oportunidad especialmente rica para estudiar el imaginario colectivo actual, no sólo debido a su importancia en la comunidad nacional, sino que también por su celebración y exaltación de la cultura cotidiana chilena, en su poesía, su uso del habla común y su actitud crítica hacia las instituciones y el elitismo (Grossman, 1975; Morales, 2012; González \& Dotremon, 2014).

Lo anterior permite rastrear en las respuestas digitales a la muerte de Nicanor Parra discursos contemporáneos sobre identidad y autorrepresentación, así como también articulaciones contemporáneas de memoria chilena. Los significados expresados en estas publicaciones son extremadamente ricos ofreciendo una reveladora radiografía de la sociedad chilena. Fue evidente, tras una cuidada lectura de las publicaciones, que, a través de la mediación y remediación de los antipoemas e ideas de Parra, los usuarios de Instagram contaban una historia no sólo sobre Chile, hoy, sino que, también, sobre el Chile del mañana.

A través de las imágenes y textos compartidos, los usuarios y usuarias proyectaron a Parra como un profeta moderno, cuyas enseñanzas de crítica y "anti-tud" se vieron articuladas en imágenes y textos que problematizaron repetidamente un sistema neoliberal que ha tenido un desmedido impacto tanto en la igualdad económica como en el estado del medioambiente del país. La "anti-tud" de Parra se configura como un mensaje, un llamado para que los chilenos actúen frente a éstos y otros problemas que les afectan. Ello, a pesar de que muchas veces Parra se mantuvo al margen de movimientos políticos de su época que intentaron dar solución a los problemas identificados. En otras palabras, los usuarios más que insistir en la visión o ideas de un Parra histórico, usan sus poemas, imagen y artefactos para tejer sus narrativas propias sobre el Chile de hoy.

Al mismo tiempo, al usar su imaginación para proyectar sus ambiciones y deseos hacia el futuro, los usuarios se conectan emocional y críticamente con la contingencia actual. Estas formas de expresión hacen eco de las exigencias de cambio que han tomado forma en los últimos años: protestas estudiantiles, nuevas fuerzas políticas, un movimiento feminista activo y una revuelta social que exigió cambios radicales a las estructuras de poder imperantes. Los usuarios utilizan los discursos de la antipoesía, discursos que critican el poder y la exclusión que impone a las personas, resignificando la "chilenidad" y reconstruyendo una identidad fracturada.

La gran mayoría de las investigaciones sobre memoria chilena se han enfocado en los recuerdos traumáticos de la dictadura y los años de comisiones de verdad que le siguieron. En ese sentido, el presente estudio cubre un vacío al analizar memorias contemporáneas, a qué se refieren y qué expectativas revelan hacia el futuro, ofreciendo una metodología robusta para el análisis de la esfera pública digital. Por otro lado, se deben considerar ciertas limitaciones: factores como género, religión, clase económica y otras características individuales pueden influenciar el uso de los medios y el acceso a las redes sociales, como Instagram, lo que puede generar diversas performances de identidad nacional. En ese sentido, las representaciones fueron creadas por un grupo específico de personas que comparten un interés especial sobre Parra. Cada persona negocia su identidad de forma diferente y es necesario advertir respecto de asunciones esencialistas sobre una identidad colectiva. 
Por último, de esta investigación surgen preguntas que requieren una mayor exploración. A medida que se intensifica la sensación de crisis, se vuelve más importante que los expertos estudien con detención posibles memorias futuras en Chile para examinar en mayor detalle qué clase de represen- taciones, esperanzas y ambiciones éstas articulan. Cruces especialmente fructíferos serán aquellos que consideren el arte, las políticas públicas y la educación para generar pensamiento crítico, soluciones productivas y conversaciones sobre qué tipo de futuro nos imaginamos, y cómo llegar a él.

\section{Referencias}

Becker, D. (2017). Instagram as a potential platform for alternative visual culture in South Africa. En: M. Bunce, S., Franks, \& C. Paterson (Eds.) Africa's Media Image In The 21st Century: From The “Heart Of Darkness" To “Africa Rising" (pp.102-112). Oxo: Routledge.

Benedetti, M. (1972). Los Poetas Comunicantes. Montevideo: Biblioteca de Marcha.

Binns, N. (2006). "Introducción". En N. Binns \& N. Parra (eds.) Obras Completas \& Algo + (pp.XXIX-LXXVI). Barcelona: Galaxia Gutenberg.

Bleiker, R. (2012). Aesthetics and World Politics. Hampshire: Palgrave Macmillan. http://dx.doi. org/10.1057/9780230244375

Burgess, J. (2007). Hearing ordinary voices: cultural studies, vernacular creativity and digital storytelling. Continuum, 20(2), 201-214. http://dx.doi.org/10.1080/10304310600641737

Cardalda, E.B. \& Tirado, A. (2001). Ambiguous Identities! The Affirmation of Puertorriqueñidad in the Community Murals of New York City. En: A. Laó-Montes \& A. Dávila (eds.) Mambo Montage: The Latinization of New York (pp.207- 233). New York: Columbia University Press.

Chiriboga, L.A. (2013). En Busca De Octavio Paz: De La Historia A “Lo Otro". Quito: Casa de la Cultura Ecuatoriana.

Duguay, S. (2015, 27-29 de Julio). Is being \#instagay different from an \#lgbttakeover? A cross-platform investigation of sexual and gender identity performances [presentación en conferencia]. Social Media and Society 2015 International Conference. Ryerson University, Canadá.

El Mostrador (16 de octubre, 2020). La minuta de Allamand a las embajadas con la versión oficial sobre el estallido social y el plebiscito. El mostrador. https://www.elmostrador.cl/dia/2020/10/16/la-minutade-allamand-a-las-embajadas-con-la-version-oficial-sobre-el-estallido-social-y-el-plebiscito/

Erll, A. \& Rigney, A. (2012). Introduction: Cultural Memory and its Dynamics. En A. Erll \& A. Rigney (eds.) Mediation, Remediation, and the Dynamics of Cultural Memory (pp.1-11). Gottingen: De Gruyter. http://dx.doi.org/10.1515/9783110217384.0.1

Farinosi, M. \& Micalizzi, A. (2016). Geolocating the past: online memories after the L'aquila earthquake. En: A. Hajek, C. Lohmeier, \& C. Pentzold (eds.) Memory In A Mediated World: Remembrance And Reconstruction (pp.90-110). London: Palgrave Macmillan. http://dx.doi.org/10.1057/9781137470126_6

Foucault, M. (1991). Discipline and Punish: the birth of a prison. London: Penguin.

Foxley, A.M. (1989). Nicanor Parra: un embutido de ángel y bestia. La Época (72), 1-4.

Frith, S. (1996). Music and Identity. En S. Hall, \& P. du Gay (eds.) Questions of Cultural Identity (pp.108-127). London: Sage. http://dx.doi.org/10.4135/9781446221907.n7

Fürsich, E. (2009). In defense of textual analysis. Journalism Studies, 10(2), 238-252. http://dx.doi. org/10.1080/14616700802374050 
Gonzalez, R.E. \& Dotremon, D. (2014). The physicist who made a significant contribution. Hipertexto, (19), 63-82.

Grossman, E. (1975). The Antipoetry of Nicanor Parra. New York: New York University Press.

Guta, H. \& Karolak, M. (2015). Veiling and blogging social: media as sites of identity negotiation and expression among Saudi women. Journal of International Women's Studies, 16(2), 115-127.

Hajek, A., Lohmeier, C. \& Pentzold, C. (2016). Introduction: Remembering and Reviving in States of Flux. En: A. Hajek, C. Lohmeier \& C. Pentzold (eds.) Memory In A Mediated World: Remembrance And Reconstruction (pp.1-12). Hampshire: Palgrave Macmillan. http://dx.doi.org/10.1057/9781137470126_1

Hall, S. (1996). Introduction: Who Needs “Identity”?. En: S. Hall \& P. du Gay (eds.) Questions of Cultural Identity (pp.1-17). London: Sage.

Harju, A. (2015). Socially shared mourning: construction and consumption of collective memory. New Review of Hypermedia and Multimedia, 21(1-2), 123-145. http:// dx.doi.org/10.1080/13614568.2014.983562

Hogan, B. (2010). The Presentation of Self in the Age of Social Media: Distinguishing Performances and Exhibitions Online. Bulletin of Science, Technology \& Society, 30(6), 377-386. http://dx.doi.org/10.1177/0270467610385893

Hormazábal, R. (2017, 21 de Junio). Siete pasos posibles para reducir la desigualdad en Chile. El Mostrador. http://www.elmostrador.cl/noticias/opinion/2017/06/21/ siete-pasos-posibles-para-reducir-la-desigualdad-en-chile/

Huyssen, A. (2003). Present Pasts: Urban Palimpsests and the Politics of Memory. Stanford: Stanford University Press.

Kearney, A. (2013). Ethnicity and Memory. En: E. Keightley \& M. Pickering (eds.) Research Methods for Memory Studies (pp.132-148). Edinburgh: Edinburgh University Press.

Keightley, E. \& Pickering, M. (2013). "Painful pasts". En: E. Keightley \& M. Pickering (eds.) Research Methods for Memory Studies (pp.151-166). Edinburgh: Edinburgh University Press.

Larraín, J. (2001). Identidad Chilena. Santiago: LOM.

Larraín, J. (2010). Identidad Chilena y el Bicentenario. Estudios Públicos, (120), 5-30.

Lather, P. (2017). (Post)Critical Methodologies: The Science Possible After the Critiques. New York: Routledge.

Martín-Barbero, J. (2006). "Intervening From and Through Research Practice: Meditations On The Cuzco Workshop". En: D. Sommer (ed.) Cultural Agency in the Americas (pp.31-51). London: Duke University Press.

McKee, A. (2003). Textual Analysis: A Beginner's Guide. London: Sage.

Merriam, S. (2009.) What is Qualitative Research? En: S. Merriam (ed.) Qualitative Research: A Guide to Design and Implementation (pp.3-20). San Francisco: Wiley.

Milan, S. (2015). From social movements to cloud protesting: the evolution of collective identity. Information, Communication \& Society, 18(8), 887-900. http://dx.doi.org/ 10.1080/1369118X.2015.1043135

Morales, L. (2012). Nicanor Parra: El proyecto antipoético. Anales de Literatura Chilena, (17), 147-167. 
Nómez, N. (2003). Identidad y mito en la poesía moderna: Otra mirada sobre lo mismo. Atenea, (487), 51-67.

Nyabola, H.N. (2017). "Media perspectives and new narratives: Kenyans tweet back". En: M. Bunce, S., Franks, \& C. Paterson (eds.) Africa's Media Image In The 21st Century: From The "Heart Of Darkness" To "Africa Rising" (pp.113-115). Oxon: Routledge.

Pace, L. \& Livingston, M. (2005). Protecting Human Subjects in Internet Research. Electronic Journal of Business Ethics and Organization Studies, 10(1), 35-41.

Parra, N. (1969). Obra Gruesa. Santiago: Editorial Universitaria.

Parra, N., \& Neruda, P. (1962). Discursos. Santiago: Editorial Nacimiento.

Programa de las Naciones Unidas para el Desarrollo (2006). Desarrollo Humano en Chile. Las Nuevas Tecnologías: ¿un Salto al Futuro? http://www.cl.undp.org/content/ chile/es/home/library/human_development/las-nuevas-tecnologias---un-salto-al-futuro-.html

Rose, G. (2012). Visual Methodologies: An Introduction To Researching With Visual Materials. London: Sage.

Rowe, W. \& Schelling, V. (1991). Memory and Modernity. Popular Culture in Latin America. London: Verso.

Shellhorse, A.J. (2017). Anti-Literature: The Politics and Limits Of Representation In Modern Brazil And Argentina. Pittsburgh: University of Pittsburgh Press.

Soguk, N. (2006). Splinters of Hegemony: Ontopoetical Visions in International Relations. Alternatives, 31 (4), 77-404. http://dx.doi.org/10.1177/030437540603100402

Subercaseaux, B. (2016). Políticas Culturales en Chile: Una Perspectiva Histórica. Estudios Públicos, (144), 205-232.

Van Dijck, J. (2007). Mediated Memories in the Digital Age. Stanford: Stanford University Press.

Vivienne, S. \& Burgess, J. (2013). The remediation of the personal photograph and the politics of self-representation in digital storytelling. Journal of Material Culture, 18(3), 279-298.

Zappavigna, M. (2016). Social media photography: construing subjectivity in Instagram images. Visual Communication, 15(3), 271-292. http://dx.doi. org/10.1177/1470357216643220

\section{- Sobre la autora:}

Victoria Guzmán es académica de la Universidad del Desarrollo, abogada, diplomada en Estética y Filosofía y magíster en Industrias Culturales y Creativas de King's College London. Sus investigaciones se enfocan en memoria cultural, estéticas decoloniales y estudios de museos.

- ¿Cómo citar?

Guzmán, V. (2021). Imaginarios del futuro tras la muerte de Nicanor Parra: renegociando la antipoesía como vehículo de protesta online. Comunicación y Medios, (43), 36-49. https://doi.org/10.5354/0719-1529.2021.58504 